\title{
A sociologia nos vestibulares: uma análise dos conteúdos da disciplina nos processos seletivos de admissão nas universidades federais do Estado de Minas Gerais
}

\author{
Nara Lima Mascarenhas Barbosa ${ }^{1}$ \\ Rogéria Martins ${ }^{2}$
}

\section{Introdução}

Esse trabalho é fruto de uma pesquisa, inicialmente, intitulada: A Sociologia e o acesso ao ensino superior: uma análise dos conteúdos da disciplina nos processos seletivos de admissão nas Universidades Federais de Minas Gerais, financiada pelo Programa Institucional de Bolsas de Iniciação Científica - CNPQ e que foi concluída no ano de 2014. A pesquisa foi motivada reconhecendo que, com a aprovação da Lei n. 11.684, em junho de 2008, o ensino de sociologia tornou-se obrigatório em todas as séries do ensino médio, no âmbito da Educação Básica. Em caráter dessa obrigatoriedade, entrou para o rol de disciplinas cobradas nos exames de acesso ao ensino superior e já em 2009, as Orientações Curriculares para o Ensino Médio - OCEM apresentavam os conteúdos específicos do campo disciplinar sociológico (SILVA, et al, 2009). A sociologia passou a compor o quadro de conhecimentos e competências fundamentais do ensino médio, tornando seus conteúdos, assim, passíveis de cobrança nas provas de acesso ao nível superior.

As mudanças institucionais configuradas para os planos de acesso ao ensino superior revelaram modos de admissão diferenciados nessas instituições, exigindo conhecimentos de habilidades, competências e conteúdos previstos nos Parâmetros

\footnotetext{
${ }^{1}$ Bacharel em Ciências Sociais, Mestranda em Ciências Sociais pelo PPGCS/UFRRJ. Contato: naralmb@hotmail.com

${ }^{2}$ Socióloga, Doutora em Políticas Públicas, Professora do Departamento de Ciências Sociais da Universidade Federal de Viçosa. Contato: rogerialma@yahoo.com.br
} 
Curriculares Nacionais (PCN's) e nas Orientações Curriculares para o Ensino Médio (OCEM), seja por meio dos vestibulares tradicionais, dos processos de seleção seriada e/ou do sistema de seleção unificada (que utiliza como forma de acesso o Exame Nacional do Ensino Médio-ENEM). Diante de tal contexto tornou-se fundamental investigar sobre a institucionalização da sociologia como disciplina obrigatória no ensino médio, mais precisamente, no que se refere à maneira como seus temas e conteúdos foram e vem sendo cobrados em vestibulares tradicionais, provas de seleção seriada e no Exame Nacional do Ensino Médio - ENEM, desde o momento em que ela se institucionaliza como disciplina obrigatória do nível médio, integrando às orientações curriculares para o ensino médio em 2009 até os dias atuais ${ }^{3}$.

Visto que os estudos que tomam a sociologia no ensino médio como objeto de análise, ainda são incipientes, principalmente devido ao seu histórico de intermitência nos currículos da educação básico, percebeu-se a importância de analisar a reinserção da disciplina nesse segmento de ensino, seus entraves e dilemas na atualidade, considerando essa nova versão de institucionalização disciplinar para a sociologia. Essencialmente, no que concerne a efetividade da lei que a torna obrigatória, bem como, os desafios que se mostram perante sua legitimidade. Nesse sentido, o presente trabalho tem por objetivo fazer uma reflexão acerca da consolidação da sociologia enquanto campo disciplinar, através da análise do modo como seus conteúdos vêm se apresentado nos processos seletivos de admissão ao ensino superior.

Tendo em vista que o Ensino Médio tem se configurado, em parte, como um passaporte para o ensino superior, torna-se essencial investigar como a sociologia tem se configurado nesses espaços. Neste caso, o trabalho se propõe a fazer uma verificação acerca da cobrança dos conteúdos de sociologia nos processos seletivos de admissão ao Ensino superior das Universidades Federais do Estado de Minas Gerais. Desse modo, buscando o cumprimento de tais proposições, orientaram-se a análise das provas de admissão das onze Universidades Federais de Minas Gerais, como também as provas do Exame Nacional do Ensino Médio - ENEM, no período de 2009 a 2013.

A opção por analisar os processos seletivos das Universidades Federais do Estado de Minas Gerais está ligada, sobretudo, ao fato de haver especificidades desse Estado para com o ensino de sociologia. Um dessas especificidades é a recorrência, da

${ }^{3}$ Reitera-se que, para efeito dessa pesquisa, o estudo cobriu o período de 2009 a 2013. 
Constituição Estadual de Minas Gerais, desde 1989, determinar como obrigatórios o ensino de filosofia e sociologia no Segundo Grau ${ }^{4}$.

No intento, primeiramente, o trabalho versa sobre o percurso legal do acesso ao ensino superior no Brasil. Na seqüência, serão descritas os passos e métodos utilizados para a realização desta pesquisa, bem como, sobre a disposição dos conteúdos da disciplina nos processos seletivos, enquanto seus resultados.

\section{Histórico do acesso ao ensino superior}

Embora o foco da discussão nesse trabalho seja o conteúdo de sociologia; o pano de fundo revela um mecanismo burocrático excludente ajustado nos processos seletivos de acesso ao ensino superior, na história da educação no Brasil. Não se pode deixar de reconhecer nesse debate, diferentes elementos que configuraram a trajetória da institucionalização do acesso e da democratização do ensino superior. Nesse sentido, o debate recupera um inventário sistemático de implementação de políticas, ainda sob a égide de uma suposta meritocracia.

A gênese da implantação do ensino superior no Brasil assumiu, desde seu início, já no período colonial e no Império características privatistas, uma vez que foi assumida, por cursos superiores isolados e, sobretudo voltado primeiro, para compor uma necessidade dos eclesiásticos (jesuítas) e depois para formar os quadros políticoadministrativos do Estado. Somente em 1911, que se observou a institucionalização do acesso ao ensino superior por meio de Decretos Federais, legitimando uma avaliação para o acesso. Segundo Cunha (2000), é o Decreto $n^{\circ} 8.659$, de 5 de abril de 1911, que instituiu o Exame de Admissão. Esses exames resolviam, conforme regulação legal do documento original no Artigo 65, parágrafo $1^{\mathrm{o}} \mathrm{em}$ “[...]prova escripta em vernaculo, que revele a cultura mental que se quer verificar e de uma prova oral sobre línguas $e$ sciencias", para todos os aspirantes ao ensino superior, independente de qual escola secundária viessem, tinham de prestar o exame.

O nome vestibular origina-se, num decreto posterior a esse primeiro, com o Decreto $\mathrm{n}^{\mathrm{o}}$. 11.530, de 18 de março de 1915, que estabelece uma mudança, de caráter formal, alterando a nomenclatura desses exames para Vestibular. O instrumento

\footnotetext{
${ }^{4}$ A apresentação do termo Ensino Médio só passa a ser aplicado com a Lei n. 9394/96.
} 
normativo também regulou sobre a institucionalização da formação de nível básico, uma vez que exigia além das avaliações apresentadas no primeiro Decreto, certificações nessas etapas do ensino, ou seja:

\begin{abstract}
ao candidato era exigido apresentar certificado de aprovação das matérias do Curso Ginasial realizado em estabelecimentos de ensino público, especificamente o Colégio D. Pedro II, que era Federal ou de outros Estaduais no modelo daquele. Os candidatos egressos de escolas privadas tinham que ser aprovados nessas escolas para serem também certificados e terem acesso à educação superior (SANTOS, 2012, p. 3).
\end{abstract}

Se hoje os processos seletivos se justificam em razão do número de vaga - enquanto critério para selecionar; nem sempre foi assim... A realidade social no Brasil não carecia de operar nesse sentido. Existia limite e restrição de grande parte da população para acessar essa etapa de formação, por questões econômicas. A conquista de nível elementar já era excludente, quiçá o ensino superior. Nesse sentido, a constituição do número de vagas, só foi justificar-se na década de 1925, com a sociedade se complexificando. O acesso ao ensino superior no Brasil já era tão restrito, por questões econômicas (somente famílias mais abastadas conseguiam tal proeza) que, somente o Decreto $\mathrm{n}^{\mathrm{o}} 16.782$-A de 13 de janeiro de 1925, passa a regular o critério de vagas nas instituições. Segundo Cunha (2000) até esse Decreto, todos os estudantes que fossem aprovados no exame tinham direito à matrícula. A linha política de caráter seletiva e discriminatória no Exame Vestibular segue nos anos de 1925, com mudanças, de caráter substancial. O referido Decreto $n^{\circ}$ 16.782-A de 13 de janeiro de 1925 acentuou ainda mais o caráter seletivo e discriminatório dos Exames Vestibulares, pois a partir desse ficou estabelecido o critério de vagas nas instituições.

Esse modelo classificatório e seletivo dos dias atuais tem origem nesses decretos de 1911 a 1925, estabelecendo critérios diferenciados a cada momento, em razão das demandas pelo acesso ao ensino superior. Ainda que o acesso estivesse "aberto" para os egressos do ensino básico - ginasial e secundário, as condições materiais concretas não facilitavam esse acesso, porque as políticas educacionais no Brasil assumiram caráter dualista estrutural ${ }^{5}$, durante muitos anos. Somente na década de 1990 mudanças significativas foram operadas, mas mudando pouco esse caráter, em razão da qualidade de ensino público, em detrimento do ensino privado. Do ponto de vista dos conteúdos,

\footnotetext{
${ }^{5} \mathrm{O}$ legado histórico do dualismo estrutural da educação básica revelou a teoria do dualismo escolar apresentando o perverso percurso da escola pública brasileira: escola do conhecimento para os ricos, escola do acolhimento social para os pobres, segundo Libâneo (2012).
} 
os instrumentos de avaliação, ao longo desses anos, não sofreram alterações substanciais. O conhecimento continuou a ser explorado de forma linear, não favorecendo a reflexão do candidato e priorizando o conhecimento memorizado nos processos de seleção, orientados pelos conteúdos do ensino médio. ${ }^{6}$

Assim, o inventário histórico desse modelo seletivo começa com a introdução de exames de admissão, em 1911; depois aperfeiçoa o processo seletivo passando a exigir certificações de conclusão do ensino secundário, em 1915 e, por fim, apresentando a limitação de vagas e introduzindo o critério classificatório, com a Reforma de 1925, onde o diretor da faculdade fixava o número de vagas anuais para os estudantes aprovados se matricularem por ordem de classificação, até complementar as vagas, onde os demais teriam de fazer novo exame. (CUNHA, 2000).

O movimento de exigência da reforma do ensino superior no Brasil na década de 1950, por professores progressistas imprimiram no Ministério da Educação e Cultura algumas modificações da legislação, com a Lei de Reforma do Ensino Superior n. 5.540 de 28 de novembro de 1968. Foi com essa Lei que se estabeleceu o vestibular unificado e fixando a orientação para se utilizar os conteúdos curriculares do segundo grau nos processos seletivos para acesso ao ensino superior ${ }^{7}$. Uma perspectiva que ainda não tinha sido contemplada nas legislações anteriores.

Com a nova configuração legal, inspirada na nova Constituição Federal de 1988, debates calorosos em torno da aprovação da nova Lei de Diretrizes e Bases da Educação Nacional, a Lei n. 9.394, de 20 de dezembro de 1996 elimina o termo vestibular, introduzindo a expressão processo seletivo, estabelecendo, também, a autonomia das instituições em criar novos mecanismos de acesso que estabelecessem articulação com o Ensino Médio. O Exame Nacional do Ensino Médio - ENEM nasce no contexto de um “estado avaliador", que segundo Afonso (2005) assume características de políticas adotadas pelos governos neoliberais, enfatizando, sobretudo o dispositivo da avaliação, significando, um ethos competitivo de lógica de mercado. Historicamente é possível afirmar que o Governo Federal assume de forma centralizada a coordenação desse acesso ao ensino superior.

\footnotetext{
${ }^{6}$ Por fidelidade conceitual, o termo ensino médio é cunhado apenas para explicar essa etapa do ensino, uma vez que ao longo das mudanças legais o termo variou de Ensino Secundário, Segundo Grau e, por fim, Ensino Médio.

${ }^{7}$ Grifo das autoras.
} 


\section{O caminho metodológico}

Para a obtenção dos resultados, dessa pesquisa, o trabalho se reportou a uma pesquisa qualitativa, onde primeiramente, foi realizado um levantamento acerca das características dos processos seletivos das onze Universidades Federais do Estado de Minas Gerais. Os modelos de acesso foram configurados no de período de 2009 a 2013, caracterizados por acessos de: vestibular tradicional, avaliação seriada e ENEM, sendo com a cobertura do Sistema de Seleção Unificada - SISU ou não.

As informações desses modelos de acesso foram efetuadas, em grande parte, por meio de buscas nos sites oficiais das Universidades, bem como, em sites sobre vestibulares. Contudo, além da pesquisa via internet, também foi feito contato com todas as onze universidades, por telefone e também por e-mail, para confirmação de alguns dados. O contato foi necessário, principalmente para esclarecer dúvidas sobre as informações não constantes nos sites. A técnica de análise dos conteúdos foi utilizada nas provas dos processos de seleção, para identificar a exposição dos conteúdos da disciplina de sociologia nas provas de acesso ao ensino superior dessas universidades.

Para fins de operacionalização da análise dos conteúdos das provas, utilizou-se categorias: "conteúdo disperso e conteúdo especifico", para classificar a disposição dos conteúdos das provas. Assim, disperso foi uma atribuição de conteúdo de sociologia quando se encontrava diluído em questões referentes a outras disciplinas das ciências humanas. Onde o aluno não precisa de um conhecimento específico de conteúdos da sociologia, ciência política e antropologia. E específico, para uma atribuição de conteúdo cobrava os conhecimentos e competências da disciplina em suas provas de seleção, ou seja, o aluno para responder as questões teria que ter um conhecimento mínimo, prévio nesse campo disciplinar. Entretanto, para a categoria "conteúdo disperso", houve a necessidade de se ter uma melhor definição do tipo de conteúdo que poderia se considerar próprio da sociologia, ou melhor, de se definir o que constitui um conteúdo disperso. Uma vez que existem conteúdos, temas e categorias de domínio comum entre as disciplinas de ciências humanas, que no caso são história e geografia. Ex. desigualdade social pode-se discutir nas ciências sociais, na geografia, na histórica. No entanto, cada campo possui um paradigma próprio de interpretação. 
Nesse sentido, optou-se por uma classificação ampla da sociologia, ou seja, somente questões que se mostravam ser claramente próprias das outras áreas (História e Geografia), foram deixadas de lado. Questões que envolviam conceitos que são considerados conteúdos de sociologia pelos documentos legais, como desigualdades sociais, classes sociais, trabalho, globalização entre outros, foram considerados conteúdos específicos; questões que traziam como "textos base" assuntos, temas, conceitos ou mesmo textos de autores das ciências sociais, dentro das provas de outras disciplinas da área de ciências humanas foram consideradas questões de conteúdos dispersos.

Visto isso, foram analisados um total de 45 processos seletivos de vestibular, 56 processos trienais de avaliação seriada (das Universidades que possuíam esse tipo de avaliação, ou seja, um total de seis Universidades), totalizando, assim, 101 processos de seleção analisados no período de 2009 a 2013, em todas as onze universidades federais mineiras. Além dos processos dessas instituições analisaram-se também as 05 edições do Exame Nacional do Ensino Médio- ENEM, realizadas neste mesmo período.

\section{Os modelos de acesso - a parafernália institucional}

Para a investigação dos conteúdos de sociologia nos exames de acesso ao ensino superior necessitou, primeiramente, a realização de levantamento prévio da gestão da estrutura organizativa dos processos seletivos das 11 Universidades Federais do Estado de Minas Gerais, considerando que o período coberto pela pesquisa 2009-2013 caracterizada por diferentes formas de acesso.

Nesse levantamento consideraram-se apenas as formas de ingresso para os cursos presenciais de graduação, deixando de lado os processos feitos para cursos a distância. Assim, como se pode perceber a seguir, cada universidade realiza seu processo de admissão de modo particular, diferenciando-se assim em cada uma delas.

A composição dos processos de seleção em cada uma dessas universidades; foram observados quando se davam com a ocorrência pelo SISU; se mantinham processos de avaliação seriada juntamente com o exame do vestibular e/ou concomitante ao ENEM. Nesse sentido, três modelos de acesso foram configurados 
nesse período definido pela pesquisa, nas universidades federais mineiras: vestibular tradicional, avaliação seriada e ENEM, sendo com a cobertura do SISU ou não.

Para efeito de esclarecimento, vale definir cada modelo de acesso:

a. Vestibular tradicional: forma de acesso particular de cada universidade, no qual as próprias efetivam suas provas de admissão. Seja como forma de ingresso único, seja como parte do ingresso (onde há provas de segunda fase).

b. Avaliação seriada: processo de avaliação ou de seleção seriada é uma forma alternativa de ingresso, onde o aluno não precisa fazer o vestibular tradicional, as provas são seqüenciais e realizadas ao final de cada série do ensino médio. Geralmente são três exames no total. Em algumas universidades a terceira etapa é o próprio vestibular não havendo assim uma prova específica do processo seriado. Atualmente, com a adesão ao SISU alguns desses processos têm exigido o ENEM como terceira etapa.

c. ENEM/SISU: O SISU - Sistema de Seleção Unificada é um sistema informatizado do Ministério da Educação no qual as Instituições de Ensino Superior oferecem vagas para os participantes do ENEM - Exame Nacional do Ensino Médio.

Cada universidade, mantém certas particularidades com relação à forma de ingresso. Assim, como se pode perceber a seguir, cada universidade realiza seu processo de admissão de modo particular, diferenciando-se assim em cada uma delas:

$\mathrm{Na}$ Universidade Federal de Viçosa (UFV) o ingresso é anual. Seu processo de seleção até 2011 se dava pelo vestibular tradicional. Em 2012 a UFV adere ao SISU, assim, atualmente seu processo ocorre por duas entradas: pelo SISU - Sistema de Seleção Unificada, desde 2012, e através do Programa de Avaliação Seriada para Ingresso no Ensino Superior - PASES. O SISU é responsável por 80\% do preenchimento das vagas e o PASES é responsável por $20 \%$ das vagas. Esse programa funciona com base em processo trienal, onde os alunos do $1^{\circ}$ e do $2^{\circ}$ ano do ensino médio realizam provas com base no conteúdo estudado nessas séries, já os estudantes do $3^{\circ}$ faziam as provas do vestibular. Atualmente, desde a adesão da universidade ao SISU, a terceira fase do PASES se dá com base nas notas do ENEM. Com isso, o período de análise da pesquisa (2009 a 2013), identificaram-se 03 processos seletivos de 
vestibulares da UFV, os processos dos anos de: 2009, 2010 e 2011 e 09 processos do PASES : 2009 I e II/2010 I e II/ 2011 I e II/ 2012 I e II/ 2013 I.

A Universidade Federal de Uberlândia (UFU) possui ingresso semestral, sendo um no primeiro semestre do ano e o outro no segundo semestre. Em 2009 a universidade realizou o processo tradicional do vestibular. A partir do processo de seleção 2010-1, ou seja, do primeiro vestibular de 2010, a UFU utilizou o ENEM como $1^{\mathrm{a}}$ fase do vestibular, tendo como $2^{\mathrm{a}}$ fase o vestibular tradicional, de responsabilidade da instituição. O segundo processo seletivo de ingresso do ano de 2010 (2010-2) se deu integralmente com base no vestibular tradicional. Já o processo de seleção 2011-1, teve o ENEM como $1^{\text {a }}$ fase para o campus de Uberlândia, e a prova especial de vestibular para outros campi da UFU. O processo de seleção 2011-2, por sua vez, ocorreu através do vestibular.

Em 2012, pela primeira vez, o processo de seleção seu deu integralmente através do SISU. Já no segundo processo seletivo deste mesmo ano, 2012-2, a UFU volta a ter o seu vestibular tradicional. O mesmo ocorre em 2013, no primeiro semestre do ano, 2013-1, a seleção acontece por meio do SISU, e no segundo semestre, 2013-2, a universidade retorna com o vestibular.

Dessa forma a UFU utiliza como forma de admissão, tanto o SISU quanto o vestibular tradicional. Além disso, a universidade também conta um Programa de Avaliação Seriada como forma de ingresso. Até 2009, o processo de seleção seriada se denominava 'PAIES- Programa Alternativo de Ingresso ao Ensino Superior'. Em 2010, o programa mudou de nome, passando a ser "PAAES- Programa de Ação Afirmativa de Ingresso no Ensino Superior". As vagas desse programa são destinadas exclusivamente aos alunos da rede pública. Como se pode ver, a Universidade ainda não acatou um método único de seleção ${ }^{8}$. Nessa universidade foram analisados 07 processos de vestibular da UFU: 2009-1/2009-2/2010-2/2011-1/2011-2/2012-2/2013-2 e 12 processos do PAIES/PAAES: 2009/2010 I,II e III/2011 I,II e III/2012 I,II e III/ 2013 I e II.

\footnotetext{
${ }^{8}$ Segundo o pró-reitor de graduação da UFU, Waldenor de Moraes, isso se dá pelo fato da UFU querer tomar uma decisão definitiva sobre suas formas de admissão embasada em pesquisas e resultados. Assim o Conselho de Graduação (Congrad) entendeu que não deve mudar definitivamente sem antes fazer uma análise comparativa. A entrevista com o pró-reitor está disponível em < http://www.correiodeuberlandia.com.br > acessado em: 13 de mar. 2014.
} 
A Universidade Federal do Triângulo Mineiro (UFTM) possui entrada anual. Seu processo de admissão se deu por meio do vestibular tradicional, de inteira responsabilidade da instituição, até 2013. A partir desse o ano a Universidade extingue o vestibular passando a utilizar como forma de entrada apenas o SISU. Assim, para o ingresso na instituição em 2014 seria necessário se inscrever no ENEM 2013. Entretanto, nesse ano a universidade realizou um vestibular especial, o vestibular de inverno 2013. Desse modo, foram analisados os 05 exames de vestibular realizados pela instituição, de 2009 a 2013.

A Universidade Federal de Ouro Preto (UFOP) possui entrada semestral. Começa a utilizar o ENEM em 2009, como $1^{\text {a }}$ fase do vestibular. O mesmo procedimento ocorre nos dois processos de seleção do ano de 2010. A partir de 2011, a UFOP adere ao SISU como única forma de ingresso. Sendo assim, foram analisados 04 processos de seleção da UFOP: 2009-1/2009-2/2010-1/2010-2.

A Universidade Federal de Minas Gerais (UFMG) possui entrada anual. Começa a utilizar o ENEM em 2011, como $1^{\text {a }}$ etapa do vestibular, mantendo o vestibular como $2^{\mathrm{a}}$ fase. Ao todo, foram 05 vestibulares realizados pela instituição.

A Universidade Federal de São João Del Rei (UFSJ) possui ingresso semestral. A universidade adere ao SISU em 2013, assim o processo de seleção do segundo semestre desse ano, 2013-2, se deu, integralmente, com base no ENEM. Em 2012, a universidade já havia adotado o ENEM como $1^{\text {a }}$ fase do processo de seleção. Atualmente, o processo de admissão na UFSJ se dá pelo SISU e pelo Programa de Avaliação Seriada (PAS). Foram analisados, assim, 08 processos do vestibular: 2009/2010-1/2010-2/2011-1/2011-2/2012-1/2012-2/2012-1 e 5 edições do PAS :2011 II/2012 I e II/2013 I e II.

A Universidade Federal de Alfenas (UNIFAL) possui entrada semestral. Desde 2010 a Universidade aderiu ao Sistema de Seleção Unificada- SISU como forma de ingresso. Desse modo, a análise ocorreu em apenas 02 os processos de seleção do vestibular: 2009-1 e 2009-2.

A Universidade Federal de Lavras (UFLA) possui entrada semestral. Em 2010, o primeiro processo seletivo do ano, 2010-1 ocorreu com por meio do SISU. Em 2010-2, voltou com o processo de vestibular. Em 2011 a universidade aderiu ao SISU, mantendo o seu Programa de Avaliação Seriada (PAS). A pesquisa analisou 03 
processos de vestibular:2009-1/2009-2/2010-2 e 6 edições do PAS 2009 I e II,2010 I e II, 2011 I e II.

A Universidade Federal de Juiz de Fora (UFJF) adotou o SISU como forma de ingresso em 2013, mantendo também seu programa de avaliação seriada PISM Programa de Ingresso Seletivo Misto. Assim, foram analisados 04 processos do vestibular da UFJF: 2009/2010/2011/2012 e 12 processos do PISM: 2009 I, II e III/ 2010 I,II e III/ 2011 I,II e III/ 2012 I,II e III.

A Universidade Federal do Vale do Jequitinhonha e Mucuri (UFVJM) adota o SISU em 2009, mantendo o SASI - Processo de Seleção Seriada, como forma de ingresso. Com isso, analisou-se apenas as provas do SASI. Assim, foram analisados 12 processos: 2009 I, II e III/ 2010 I, II e III/ 2011 I e II/2012 I e II/ 2013 I e II.

A Universidade Federal de Itajubá (UNIFEI). Tiveram dois ingressos em 2009. Nos anos de 2010 e 2011 houve apenas um ingresso. Em 2012, a universidade adere ao SISU. Com isso, foram analisados 04 processos de vestibular da UNIFEI: 2009-1/20092/2010/2011.

\section{Os conteúdos específicos e dispersos da sociologia}

Durante a pesquisa percebeu-se que os conteúdos de Sociologia se mostraram de forma esparsa em 09 das 11 universidades. Sendo exigidos seus conhecimentos específicos somente em duas delas: na Universidade Federal de Uberlândia e na Universidade Federal de Lavras. De modo geral, tais conteúdos se apresentaram em questões que envolviam temas e conceitos de domínio comum, como: globalização, desigualdades sociais, classes, questões raciais, políticas e econômicas. Observou-se também, que esses conteúdos disseminados estavam presentes principalmente em questões das provas de História e Geografia, Língua Portuguesa (em textos para interpretação), Redação e também nas provas de Filosofia. Sobre isso, vale ressaltar que enquanto a sociologia e filosofia aparecem como conteúdo obrigatório, a filosofia se destacou mais no período coberto da pesquisa, nas universidades federais mineiras. A sociologia foi cobrada de forma específica em apenas duas universidades, em detrimento de conhecimentos (conteúdos) de filosofia, foram cobrados em quatro universidades. Sobre isso, é importante lembrar que as mesmas universidades que 
possuem a sociologia como matéria em seus processos de seleção, a UFU e a UFLA, também exigem questões especificas de filosofia. No entanto, a UFMG e a UFSJ exigiram apenas os conhecimentos da Filosofia.

Dessa forma, analisando a parte reservada às Ciências Humanas nos processos de admissão dessas universidades percebeu-se a presença de conteúdos de sociologia dispersos nas questões de filosofia. Vale dizer, que devido grande aproximação entre o campo da Filosofia e das Ciências Sociais, e também pelo fato de alguns autores fundamentais da sociologia também serem essenciais na área da filosofia, fazer uma distinção entre o que eram conteúdos próprios à filosofia e sociologia, não foi uma tarefa fácil. Entretanto, buscaram-se considerar conteúdos esparsos apenas questões que envolviam temas e conceitos de domínio comum como, por exemplo: política e democracia. Nesse intento, nas provas de Filosofia encontramos temas como: vida pública e vida privada, utilitarismo, Estado, entre outros. Os autores mais citados nos textos base são: Hannah Arendt, Stuart Mill, Hobbes, Maquiavel, Tocqueville, Locke e Montesquieu.

Nas provas de Geografia, tanto dos vestibulares como dos programas de avaliação seriada, questões com as temáticas: gênero e trabalho, desigualdades sociais e apropriação do espaço, globalização, movimentos sociais urbanos, relações de trabalho no contexto global, relação rural x urbano, mulher no mercado de trabalho e mudanças nas taxas de natalidade, entre outras. Nas provas de Geografia também encontramos questões que tinham como base textos de autores conhecidos das Ciências Sociais, os nomes que apareceram foram: Anthony Giddens, Norbert Elias e Manuel Castells.

Já nas provas de história, as temáticas das questões foram: o negro no Brasil, organização da sociedade no Brasil colônia, desigualdades raciais, democracia e cidadania, formação e organização do Estado, movimentos sociais e relações de trabalho (no contexto da Revolução Industrial). Como nas provas de Geografia, também encontramos textos de autores das Ciências Sociais, como textos base das questões, os principais autores citados foram: Tocqueville, Hobbes, Rousseau, Montesquieu, Maquiavel, Norbert Elias e Karl Marx.

Nas provas de Língua Portuguesa, por sua vez, os temas de sociologia se apresentavam em textos, onde era necessário apenas ter a habilidade interpretativa do mesmo. As temáticas dos textos que apareceram nos processos das universidades 
analisadas são: violência contra a mulher, internet e mudanças na comunicação entre as pessoas, desigualdades sociais, discriminação racial e tribos urbanas. Os temas propostos para as redações foram semelhantes aos das provas de Língua Portuguesa: violência contra a mulher, discriminação racial, internet e mudanças na comunicação e desigualdades sociais.

Contudo, a cobrança de conteúdos dispersos não exigia conhecimentos de Sociologia. Os conhecimentos adquiridos em outras disciplinas, como Geografia e História pareciam ser suficientes. Uma vez que tais questões foram elaboradas dentro dos domínios dessas disciplinas. Assim, as questões sobre desigualdades sociais, por exemplo, eram, geralmente, articuladas a desigualdade de apropriação do espaço. As questões sobre movimentos sociais, Estado Moderno e democracia deveriam ser respondidas de acordo com os conhecimentos históricos sobre o tema e, por fim, uma questão sobre globalização, que tinha um trecho da obra Modernidade e Identidade de Anthony Giddens (2002), como texto base, não exigiam nenhuma interpretação sobre o texto, e tampouco, o conhecimento sobre o autor. O texto era basicamente ilustrativo para uma pergunta pontual sobre como havia se dado o processo de globalização. Visto isso, a presença de conteúdos dispersos de sociologia não demandava um conhecimento básico acerca da disciplina. Ao contrário dos conteúdos específicos, que de fato, exigem um conhecimento prévio sobre seus temas, conceitos e autores.

Nas universidades que, efetivamente, exigiam os conteúdos específicos da disciplina, como a UFU e UFLA, se cobravam em suas questões conhecimentos acerca dos conceitos e teorias tratados pelos clássicos da Sociologia como: Durkheim, Marx e Weber. Além das questões sobre esses autores, surgiram questões sobre movimentos sociais e ação coletiva, cultura e simbologia, Escola de Frankfurt, sexualidade e gênero. Tendo em vista, tanto os exemplos anteriores de questões com conteúdos dispersos, como o exemplo acima, de uma questão que traz conteúdos específicos, percebe-se que nos primeiros exemplos, o fato dos conteúdos estarem disseminados, não garantiram relevância à disciplina. Uma vez que seus conhecimentos não são necessários para se responder a questão. Ao contrário do segundo exemplo, onde os conhecimentos e competências da disciplina são fundamentais para a resolução do problema da questão.

\subsection{Os conteúdos de sociologia nos processos seletivos das universidades federais mineiras}

UFSC, Florianópolis - http://dx.doi.org/10.5007/1806-5023.2015v12n2p124- ISSN: 1806-5023 
Com a finalidade de se fazer uma análise mais detalhada dos dados os modelos seletivos foram analisados separadamente: processos seletivos de vestibular, as provas dos Programas de Avaliação Seriada, e as provas do ENEM.

Dessa forma, primeiramente, se dará a exposição dos dados analisados nos 45 processos de vestibulares, em seguida mostrarão os dados coletados nos 56 processos de avaliação seriada e, por fim, farei a exposição das análises dos conteúdos das 05 edições de provas do ENEM. Dessa forma, analisamos um total de 45 exames de vestibular de dez ${ }^{9}$ das onze Universidades Federais do Estado de Minas Gerais.

\subsubsection{Sociologia nos vestibulares tradicionais}

$\mathrm{Na}$ Universidade Federal de Viçosa (UFV) foi realizada a análise de 03 processos de admissão, dos anos de 2009, 2010 e 2011. Vale lembrar que a universidade aderiu ao SISU em 2012, assim, a partir desse ano o processo passou a se dar com base nas provas do ENEM e no PASES - Programa de Avaliação Seriada. Dessa forma, ao verificar como se deu a presença dos conteúdos de sociologia nos vestibulares da UFV, percebe-se que, em nenhum dos anos analisados houve a cobrança de conteúdos específicos da disciplina. Nos anos de 2009 e 2011, os conteúdos apareceram difundidos nas disciplinas de História e Geografia. Em 2010, não apareceram questões com esse caráter disperso. Os temas aferidos nessas questões listavam conceitos como: globalização, democracia, movimentos sociais, Estado Moderno segundo Hobbes e desigualdades sociais. Embora sejam conceitos tratados pela sociologia, não era necessário ter conhecimentos sociológicos para se resolver as questões, uma vez que as discussões se davam como temas aplicado aos conteúdos de Geografia e História. Os conhecimentos adquiridos no ensino de Geografia e História, considerados demasiadamente extensos, em detrimento da sociologia, uma vez que tais questões foram elaboradas dentro dos domínios dessas disciplinas. Assim, a questão sobre desigualdades sociais, por exemplo, era articulada a desigualdade de apropriação do

\footnotetext{
9 A análise de apenas dez dessas instituições está no fato da Universidade Federal do Vale do Jequitinhonha e Mucuri- UFVJM, ter aderido ao SISU no período estudado, ou seja, 2009 a 2013, mantendo como processo próprio somente o SASI - Programa de Seleção Seriada. Com isso, tendo em vista tal fator, foram analisadas apenas as provas do SASI.
} 
espaço. As questões sobre movimentos sociais, Estado Moderno em Hobbes (O Leviatã, 1679) e democracia deveriam ser respondidas de acordo com os conhecimentos históricos sobre o tema. Considerando essa análise das provas, observa-se, assim, que a sociologia não teve o devido reconhecimento dentro dos processos seletivos dessa instituição, uma vez que sua apresentação se dá de forma esparsa.

Na Universidade Federal de Minas Gerais (UFMG) esse quadro não foi diferente. Nos 05 processos analisados, não foi encontrada a exigência de conteúdos específicos de sociologia. No entanto, vale ressaltar que, a UFMG tem por exigência os conhecimentos específicos da filosofia. Ao contrário da UFV, que também não exige os conhecimentos nessa área. Nos processos seletivos de 2010, 2011 e 2012 os conteúdos de sociologia se mostraram de forma disseminada em provas de História, Geografia e Filosofia. Esses conteúdos tinham como temática: mulher e mercado de trabalho, vida pública e vida política para Maquiavel, utilitarismo de Stuart Mill, manifestações culturais e desigualdades sociais. Nos anos de 2009 e 2013, por sua vez, não se apresentaram de nenhuma forma.

No caso da Universidade Federal de São João Del Rei (UFSJ) analisou-se 08 processos de vestibular, dos anos de 2009 a 2013. Como a universidade possui, a partir de 2009, uma forma de ingresso semestral e tendo em vista que a UFSJ adere ao SISU apenas no segundo vestibular de 2013, ou seja, no vestibular 2013-2, foram analisados os seguintes vestibulares da instituição: 2009; 2010-1; 2010-2; 2011-1; 2011-2; 2012-1; 2012-2; 2013-1. Não muito diferente das outras duas universidades apresentadas, na UFSJ também não foi constatada a presença de conteúdos específicos de sociologia. Nos vestibulares 2009; 2010-1; 2010-2; 2011-2; 2012-1; 2012-2 e 2013-1 verificaramse a presença de conteúdos dispersos em provas de História, Geografia e Filosofia, com temas como: movimentos sociais, democracia, Hobbes e sua concepção de Estado ( $O$ Leviatã, 1679), relações étnico-raciais e diferenças. No processo 2011-1 não foram identificados conteúdos com esse caráter.

A Universidade Federal de Uberlândia (UFU) foi considerada umas das primeiras universidades do país a exigir os conhecimentos e habilidades específicas da sociologia em seus processos de admissão, exigindo-os desde 1997. Contudo, a análise se dirigiu apenas de 07 processos da UFU, a partir de 2009: 2009-1; 2009-2; 2010-2; 2011-1; 2011-2; 2012-2; 2013-2. Nessa pesquisa observou-se que o UFU foi a única 
universidade que de fato deu o devido reconhecimento para a sociologia enquanto um campo disciplinar relevante, cobrando suas competências e habilidades específicas na mesma proporção que as demais disciplinas. Assim, observou-se a distribuição equitativa nas provas de sociologia e demais disciplinas. Foi observado o mesmo número de questões objetivas (10 questões) e discursivas (04 questões), que nas provas das disciplinas tradicionais. O mesmo reconhecimento dado a sociologia, também foi a dado a filosofia. Contudo, verificou-se, porém, que as provas de outras disciplinas da área de Ciências Humanas foram diagnosticadas também conteúdos dispersos de sociologia em praticamente todos os anos. Entretanto, aqui se observou que nos vestibulares da UFU houve a cobrança de conteúdos específicos de sociologia em todos os processos durante o período analisado, ou seja, de 2009 a 2013. Os temas de sociologia se que apresentaram nas provas foram: conceitos e temas trabalhados pelos clássicos da sociologia: Marx, Weber e Durkheim, Escola de Frankfut, gênero, manifestações culturais, ação coletiva, grupos sociais, movimentos sociais e controle social.

$\mathrm{Na}$ Universidade Federal de Lavras (UFLA), assim, como na Universidade Federal de Uberlândia, também encontramos a presença de conteúdos específicos da sociologia nos processos seletivos nessa universidade, nos anos de 2009, 2010, 2011, 2012 e 2013. Nesse caso, vale chamar a atenção para o fato de que a UFLA foi a única Universidade que passou a incluir os conteúdos de sociologia e filosofia em suas provas a partir da lei de obrigatoriedade do ensino dessas disciplinas. Dessa forma, nos 03 processos analisados 2009-1; 2009-2; 2010-2 observou-se que, no vestibular 2009-1, a sociologia ainda aparece de forma difundida, sendo cobrados seus conhecimentos específicos somente no vestibular 2009-2; bem como vestibular de 2010-2 também apareceu de forma específica. Assim os conteúdos dispersos foram encontrados na prova de história em questões que versavam sobre: relações raciais e migrações, e democracia e voto. Já as questões específicas tiveram como tema: violência e mídia, e definição dos termos: indivíduo, grupo, massa, público e multidão, Escola de Frankfurt e controle social e socialização. No entanto, observamos que a disciplina não foi incluída em pé de igualdade com as demais disciplinas, assim como ocorreu na UFU. Desse modo, a quantidade de questões de sociologia, e também de filosofia, eram inferiores as demais, havendo apenas duas questões específicas da disciplina. 
Já no caso da Universidade Federal do Triângulo Mineiro (UFTM) foram analisados os conteúdos de 05 processos de seleção de 2009 a 2013, se mostraram apenas na forma dispersa nas provas de história e geografia, em temas como: democracia e cidadania, globalização, relação rural x urbano, movimentos sociais, mudanças nas formas de trabalho e desigualdades sociais. Não havendo, assim, cobrança de temas e conteúdos próprios da sociologia.

$\mathrm{Na}$ Universidade Federal de Alfenas (UNIFAL), assim como a Universidade Federal do Triângulo Mineiro, não se identificou, na análise, a presença de conteúdos específicos de sociologia. No segundo vestibular do ano de 2009 verificou-se a presença de conteúdos dispersos em disciplinas como: História, Geografia e Língua Portuguesa. Os temas e conceitos tratados nessas questões tinham por base assuntos como: mulher e mercado de trabalho (vinculada à questão da queda na taxa de natalidade), formação do Brasil e matrizes étnicas, sociedade de consumo e internet e mudanças na comunicação. Já no primeiro vestibular do ano de 2009 não apareceram conteúdos com essa característica.

Esse quadro se repete na Universidade Federal de Ouro Preto (UFOP) nos 04 vestibulares analisados, não houve a presença de conteúdos específicos. Apenas esparsos nas provas discursivas de História e Geografia da segunda fase do processo seletivo de admissão, tendo os seguintes temas: divisão sexual do trabalho, globalização e desigualdades sociais, relações raciais: o negro no Brasil e mulher e mercado de trabalho. Assim, nos vestibulares: 2009-2, 2010-1 e 2010-2, os conteúdos se mostraram no modo disperso. Já em 2009-1, não houve a presença de nenhuma forma dos conteúdos da sociologia.

No caso da Universidade Federal de Juiz de Fora (UFJF), também não foram identificados conteúdos específicos de sociologia. Nos 04 vestibulares analisados: 2009; 2010; 2011 e2012 observou-se apenas a presença de conteúdos dispersos em provas de História, Geografia e Língua Portuguesa, tendo como base os seguintes temas: transformações na família, identidade cultural e diferença, mulher e ciência (ambas em textos para interpretação da prova de língua portuguesa), migrações, globalização e desigualdades sociais e modificações nas relações de trabalho.

Já nos 04 processos de seleção da Universidade Federal de Itajubá (UNIFEI) observou-se que os conteúdos quase não apareceram, nem na forma específica e nem no 
modo disperso. Apenas no vestibular 2009-1 observamos a presença de conteúdos dispersos na prova de geografia, em temas como: globalização e migrações. Nos demais processo analisados, 2009-2, 2010 e 2011 não houve a presença de nenhuma das formas. É importante dizer que no que refere a parte discursiva das provas, a UNIFEI não exigia-se as disciplinas da área de ciências humanas, sendo essa parte do processo de seleção composto somente por provas de: Física, Matemática e Inglês. As questões referentes às Ciências Humanas são cobradas apenas parte objetiva. Tal fato pode se justificar em razão dessa universidade possuir, em sua maioria, cursos de engenharia e ciências matemáticas. Vale ressaltar, que a Universidade alegou desconhecer as exigências das legislações em torno da presença da sociologia nas OCEM'sOrientações Curriculares para o Ensino Médio, mas que ainda não formulou questões próprias desse conteúdo disciplinar.

De um modo geral, observou-se que nas universidades mineiras, os conteúdos de sociologia aparecem de forma dispersa para os vestibulares tradicionais. Apresentandose como específica apenas em duas de um total de dez universidades: na Universidade Federal de Uberlândia- UFU e na Universidade Federal de Lavras- UFLA.

Dessa forma, conforme podemos ver no Quadro 01, que mostra em números a forma em que os conteúdos da disciplina se apresentaram com base nos anos analisados e nas universidades avaliadas nos 45 processos de vestibular, houve maior cobrança de conteúdos dispersos em todos os anos analisados. Em alguns momentos não apareceram, exceto no ano de 2012, único ano em que os conteúdos não apareceram ou de forma dispersa, ou de forma específica. Vemos também que o percentual da categoria "Não aparece" é maior que o percentual de questões específicas.

Quadro 01 - Percentual das características dos conteúdos nos vestibulares tradicionais

\begin{tabular}{|c|c|c|c|c|c|}
\hline $\begin{array}{c}\text { Formas dos conteúdos } \\
\text { de sociologia nos } \\
\text { vestibulares (\%) }\end{array}$ & $\mathbf{2 0 0 9}$ & $\mathbf{2 0 1 0}$ & $\mathbf{2 0 1 1}$ & $\mathbf{2 0 1 2}$ & $\mathbf{2 0 1 3}$ \\
\hline Dispersa & $53,3 \%$ & $64,0 \%$ & $56,0 \%$ & $83,0 \%$ & $50,0 \%$ \\
\hline Específica & $20,0 \%$ & $18,0 \%$ & $22,0 \%$ & $17,0 \%$ & $25,0 \%$ \\
\hline Não aparece & $26,7 \%$ & $18,0 \%$ & $22,0 \%$ & $0 \%$ & $25,0 \%$ \\
\hline
\end{tabular}

\subsubsection{Os programas de avaliação seriada}


No caso das provas dos Programas de Avaliação Seriada encontramos um quadro semelhante, no PAIES / PAAES - Programas de Avaliação Seriada da UFU. Nesse processo seletivo se percebe a cobrança de conteúdos específicos da disciplina. Nos processos de avaliação dos outros cinco programas: SASI/UFVJM; PASES/UFV; PAS/UFLA; PISM/UFJF e PAS/UFSJ, os conteúdos, quando se apresentam, são na forma disseminada. A partir dessa definição prévia acerca da presença dos conteúdos da disciplina nos processos de avaliação dos programas seriados, observa-se a apresentação dos dados que comprovam tal definição. Nesse modelo de seleção seriada foram analisados um total de 56 processos desses seis Programas de Avaliação Seriada.

Na UFJVM, a última das onze federais a ser analisada ela é considerada como uma das primeiras universidades do Estado de Minas Gerais a adotar o ENEM como forma de ingresso, desde 2009. A universidade possui o programa de seleção seriada SASI. Foram analisados 12 processos do programa, ocorridos no período de 2009 a 2013. Observou-se que não houve cobrança de questões com conteúdo específico. Os conteúdos se apresentaram de forma dispersa nas questões das provas de História e Geografia, e também no tema proposto para a Redação. Esses conteúdos tinham por base os seguintes assuntos: formação do Brasil: matrizes étnicas e miscigenação (a questão tinha como base um trecho da obra O Povo Brasileiro de Darcy Ribeiro, 1995), desigualdades sociais, as transformações na família, cidadania, inclusão e exclusão digital: desigualdades sociais, discriminação racial, multiculturalismo e políticas de cotas. Vale ressaltar, que o SASI não exige nem os conhecimentos de sociologia e os conhecimentos de filosofia. Os conhecimentos exigidos são baseados nas disciplinas tradicionais, como: Matemática, Física, Química, Biologia, História, Geografia, Literatura, Línguas (Portuguesa e Estrangeira) e Redação. Dos 12 processos analisados, somente nos processos de: 2010 ( $1^{\mathrm{a}}$ etapa), 2011 ( $1^{\mathrm{a}}$ e $2^{\mathrm{a}}$ etapa), não apareceram conteúdos de nenhuma forma.

Nos Programas de Avaliação Seriada da UFU, PAIES e PAAES, os conteúdos da sociologia apareceram, assim como nos vestibulares, de forma específica. Os assuntos abordados nas questões foram: temas e conceitos trabalhados pelos Clássicos da sociologia: Marx, Weber e Durkheim, controle social, ação coletiva e movimentos sociais, cultura e simbologia, Escola de Frankfurt e a indústria cultural, grupos sociais, gênero e sexualidade. 
Já o PISM - Programa de Avaliação Seriada da UFJF, os conteúdos se apresentaram de forma dispersa em provas História, Geografia e Língua Portuguesa, em questões sobre os seguintes assuntos: movimentos sociais, classes sociais (relacionado a população e renda), tribos urbanas, violência, relação rural urbano, gênero e sexualidade. Exceto nos processos de seleção: 2010 ( $3^{\text {a }}$ etapa) e 2009 ( $1^{\text {a }}$ etapa), onde não foi identificada a presença de conteúdos de modo disperso ou específico.

O Programa de Avaliação Seriada da UFLA, o PAS, nos seis processos analisados cobrou apenas conteúdos dispersos nas provas de História, Geografia e de Língua Portuguesa questões sobre: desigualdades sociais, relações rural e urbano, movimentos sociais, mulher e mercado de trabalho, violência e criminalidade e comunicação no mundo globalizado. Contudo, na $1^{\text {a }}$ etapa do PAS 2010, não houve exigência de nenhuma das formas de conteúdo.

No caso do PASES - Programa de avaliação seriada da UFV, o quadro foi semelhante ao da UFLA. Os conteúdos se mostraram somente na forma esparsa nas provas de História, Geografia e como tema de Redação, tendo como temas abordados: movimentos sociais urbanos, violência contra a mulher (tema da redação), transformações no mundo do trabalho, democracia, família e desigualdades sociais. $\mathrm{Na}$ $1^{\mathrm{a}}$ etapa do PASES 2010 e na $1^{\mathrm{a}}$ e $2^{\mathrm{a}}$ etapa do ano 2011, também não houve cobrança dos conteúdos. Por outro lado, nas seis edições do PAS /UFSJ os conteúdos apareceram em todos os processos analisados, na forma dispersa nas provas de História e Geografia e Língua Portuguesa (texto para interpretação), em temas como: família, redes sociais e comunicação, globalização, migrações e relação rural- urbano.

Com isso, conforme o percentual das formas que os conteúdos se apresentaram nos Programas Seriados, vê-se que a tendência maior foi a presença de conteúdos dispersos. Em segundo lugar, assim como nos vestibulares, foi o não aparecimento que mais se destacou. Como podemos visualizar no Quadro 02 abaixo. No ano de 2011 o percentual da categoria "Não aparece" foi de 36\%. Um valor acima do percentual de conteúdos específicos. 
Quadro 02 - Percentual das características dos conteúdos

\begin{tabular}{|l|l|l|l|l|l|}
\hline $\begin{array}{c}\text { Forma dos } \\
\text { conteúdos nos } \\
\begin{array}{c}\text { Programas } \\
\text { Seriados (\%)/Ano }\end{array}\end{array}$ & $\mathbf{2 0 0 9}$ & $\mathbf{2 0 1 0}$ & $\mathbf{2 0 1 1}$ & $\mathbf{2 0 1 2}$ & $\mathbf{2 0 1 3}$ \\
\hline Dispersos & $80 \%$ & $54 \%$ & $43 \%$ & $75 \%$ & $71 \%$ \\
\hline Específicos & $10 \%$ & $23 \%$ & $21 \%$ & $25 \%$ & $29 \%$ \\
\hline Não aparece & $10 \%$ & $23 \%$ & $36 \%$ & $0 \%$ & $0 \%$ \\
\hline
\end{tabular}

Considerando esses dados é possível afirmar que a sociologia vem desenvolvendo um modesto reconhecimento enquanto campo disciplinar nesses espaços. A cobrança de conteúdos dispersos revela um retraído processo de legitimidade à disciplina, considerando os exames seletivos um espaço de disputa e projeção dos campos disciplinares. Nos processos analisados a tendência dos conteúdos foi aparecer de forma dispersa, sem a possibilidade de haver alguma mudança nesse quadro, até porque algumas Universidades já extinguiram o processo de vestibular tradicional.

Sendo assim, tanto pela análise dos vestibulares tradicional, como pela pesquisa feita nas provas dos programas de avaliação seriada foi possível perceber que a sociologia não teve uma mesma projeção dos conteúdos das disciplinas tradicionais, ainda que sua exigência estivesse garantida. Fato que comprova nossa hipótese acerca do "modo disperso" que configurou o processo de inserção da sociologia no Estado. Uma vez que a edição da lei da obrigatoriedade do ensino em 1989, pela Secretaria de Educação do Estado, colocava a disciplina na parte diversificada do currículo, acarretando assim em uma "tradição dispersa". É possível compreender essa situação, dado o caráter intermitente da disciplina na etapa final da educação básica.

\subsubsection{Uma possibilidade: O Exame Nacional do Ensino Médio}

O Exame Nacional do Ensino Médio - ENEM foi criado em 1998 com o objetivo de avaliar o desempenho do estudante ao fim da escolaridade básica, no bojo de uma configuração de um estado avaliador (AFONSO, 2005). Atualmente, o exame é utilizado como forma de ingresso na maioria das universidades federais brasileiras, sendo adotado por 59 universidades federais brasileiras como processo seletivo ou parte da seleção. Considerando esse dado, foi interessante analisar também as provas do 
Exame Nacional do Ensino Médio - ENEM dos anos de 2009 a 2013. Como já foi dito ao longo do texto, quase todas as Universidades Mineiras aderiram ao SISU de alguma forma, seja como primeira fase do vestibular, seja como fase única. Dessa forma, tornou-se fundamental verificar como os conteúdos de sociologia se apresentaram no Exame.

Em 2009 o exame passou por uma reformulação, passando a ser aplicado em dois dias e composto por 180 questões de múltipla escolha sobre quatro áreas de conhecimento mais redação. Essa é a configuração atual, conforme é possível observar o novo $\mathrm{ENEM}^{10}$. Assim, versões do ENEM não apresentaram exigências e competências específicas da disciplina de sociologia; mas competências e habilidades em área do conhecimento, como Ciências Humanas e Suas Tecnologias, exigindo maior reflexão dos conteúdos. A prova da que afere a área de "Ciências Humanas e suas Tecnologias" possui 45 questões que versam sobre os conteúdos vistos nas disciplinas de Ciências Humanas, principalmente história e geografia.

$\mathrm{Na}$ análise desse estudo observou-se que, grande parte das questões se apresentou de forma dispersa, até porque a proposta do exame é ser interdisciplinar. Durante as análises das provas do ano de 2009, percebeu-se que as questões possuíam um caráter bastante esparso, mas ainda dentro dos domínios das disciplinas tradicionais. Entretanto foi possível encontrar 04 questões, ou seja, $8 \%$ do total de questões da prova de Ciências Humanas e suas Tecnologias, que se aproximavam bastante do que pode se considerar próprio da sociologia. Todavia, essas questões não pediam um conhecimento prévio sobre o assunto, eram questões interpretativas. Ou seja, era possível resolver apenas com a leitura do texto base proposto.

Tais questões tinham por base os seguintes temas: práticas sociais, crenças, formação do Brasil e democracia. Essas questões, como disse, eram bastante ilustrativas e interpretativas, não era preciso um conhecimento prévio. Apenas a leitura dos textos base das questões, bem como uma boa interpretação seria suficiente para se responder as questões.

No entanto, essas questões se diferenciam das questões de conteúdos dispersos presentes nos vestibulares, uma vez que não foram necessariamente elaboradas dentro

\footnotetext{
${ }^{10}$ Disponível em < http://vestibular.mundoeducacao.com/enem/ > Acesso em: 16 de jun. de2014
} 
dos domínios de outras disciplinas. Em 2010, encontramos 04 questões com temas como: políticas públicas de inclusão, sexualidade, contraposição da ideia de hibridação à idéia de pureza cultural, normas e regras morais. Vale dizer que esta última traz como base um texto de Habermas. Todavia, percebe-se que, nesse ano, embora as questões ainda tivessem um caráter interpretativo, algumas questões já exigem um conhecimento além da mera leitura do texto.

No ano de 2011, encontramos 06 questões com um caráter mais aproximado de um conteúdo especifico, ou seja, 13\% do total de questões. Essas questões tinham como foco os seguintes assuntos: normas morais, internet e movimentos sociais, mudanças na esfera do trabalho, democracia e mídia e os impactos sócio culturais da TV. Em 2012, encontramos 06 questões com conteúdos que podem ser considerados próprios de sociologia, na prova de Ciências Humanas e suas Tecnologias. Essas questões versavam sobre: a reivindicação dos direitos culturais das minorias (a pergunta tinha como base um texto de Habermas), democracia, formação da identidade cultural afro-brasileira, o processo civilizador de Norbert Elias, violência e disciplinarização dos corpos.

Já em 2013 foram identificas 08 questões com esse caráter. Essas questões tinham, na maioria das vezes temas como: representações sociais e moral, manifestações e identidades culturais, gênero (representação do feminino a partir do texto base), democracia, cidadania (direito a diversidade sexual), trabalho, movimentos sociais e uma questão sobre Karl Marx.

Vale também ressaltar que nas provas de 2010 a 2013, identificamos muitas questões próprias da filosofia. Nisso é importante retornar ao caso das universidades mineiras, e lembrar que a filosofia teve uma maior "representação" ou mesmo "reconhecimento" nos processos de seleção que a sociologia, sendo seus conteúdos exigidos em quatro universidades: UFU, UFLA, UFMG e UFSJ. É possível justificar devido ao fato de alguns autores terem identificação nas duas áreas. Assim, "a opção pela Filosofia também estaria "contemplando" a Sociologia".

Contudo, percebe-se que o ENEM, embora não traga a sociologia como uma disciplina específica, uma vez que as questões são de Ciências Humanas e suas Tecnologias, esse processo seletivo "reservou" algum espaço para a disciplina. Ainda de maneira tímida, as poucas questões que se apresentaram com um caráter mais aproximado das especificidades e dos domínios da sociologia, colocam o ENEM como 
um espaço em potencial representação no que se refere à legitimidade da Sociologia enquanto campo disciplinar ${ }^{11}$.

\section{Conclusão}

A conclusão de que a sociologia se consolidou de forma retraída enquanto campo disciplinar nesses espaços, marca a condição de uma trajetória fragmentada da sociologia na educação básica. Seus conhecimentos aparecem em sua maioria dispersa, mas não de forma específica o que não garantiu uma pretensa representação para a disciplina na comunidade escolar. O longo período de intermitência da disciplina nos currículos do ensino básica aliado ao processo de insulamento e invisibilidade (SARANDY, 2007), impediram que os conhecimentos de sociologia fossem identificados e considerados significativos nesse campo em disputa no processo de hierarquização de saberes. Não se tendo, atualmente, conhecimento de suas funções formativas e educativas.

Contudo, cabe aqui ressaltar que, apesar das questões colocadas e do fato do ensino de sociologia estar ainda vivenciando um contexto conturbado, é bom lembrar que ocorreram mudanças significativas que tem se mostrado como possibilidades para a consolidação do ensino da disciplina, como por exemplo, a ampliação dos cursos de licenciatura em ciências sociais através do REUNI, a retomada da preocupação com o ensino da disciplina que tem desde seu retorno, as escolas fomentado calorosos debates e pesquisas em torno do tema, entre os cientistas sociais; bem como novas experiências proporcionadas pelo Programa de Incentivo a Bolsa de Iniciação a Docência- PIBID sociologia e o crescimento do debate em torno da definição do currículo da sociologia na educação básica. Esses eventos têm marcado presença nas escolas dando visibilidade a importância da sociologia, de modo a promover uma nova direção ao seu percurso disciplinar. Outro dispositivo importante nessa consolidação é o livro didático no Plano Nacional do Livro Didático.

Paralelo a esses processos a estrutura de acesso ao ensino superior também se reformula, com o novo formato do ENEM, que tem modificado a dinâmica de acesso

\footnotetext{
${ }^{11}$ Essa afirmação ganha destaque na edição do ENEM 2014, que não foi objeto de análise desse estudo, mas por curiosidade investigativa das autoras, numa leitura exploratória, verificou-se um crescimento significativo do conteúdo de sociologia nessa edição a ser considerado na categoria "específico".
} 
nas instituições federais de ensino superior e tem colocado os conteúdos da disciplina, ainda que no pano de fundo, um universo de conteúdo familiar a disciplina, o que de certa forma a populariza. Por outro lado, a nova reforma do ensino médio, exige uma reflexão cuidadosa, por parte dos profissionais das Ciências Sociais, uma vez que há uma pretensão explícita de segmentação dos conteúdos em áreas de conhecimento. Isso pode retomar a diluição dos conteúdos, das ditas "ciências humanas".

Entretanto, diante do que esse trabalho se propôs a analisar, ao longo desta pesquisa, observou-se que em Minas Gerais, a legislação fez com que a disciplina se apresentasse apenas na parte diversificada do currículo, criando assim uma "tradição dispersa" no que se refere aos conteúdos da disciplina. Reitera-se, contudo, que sua apresentação como específica, foi observada apenas em duas de um total de onze universidades: Universidade Federal de Uberlândia- UFU e Universidade Federal de Lavras- UFLA.

Nesse sentido, vale dizer que a lei da obrigatoriedade do ensino de sociologia, revelou um modesto impacto sobre as universidades Federais do Estado. A única universidade que abriu espaço para cobrança dos conteúdos específicos de sociologia em seus processos de seleção após a implementação da lei foi a UFLA. A Universidade Federal de Uberlândia já cobrava os conteúdos de sociologia muito antes de a referida lei entrar em vigor, e nesse sentido, não foi a configuração de uma normativa legal que justifica a aplicação desses conteúdos; mas sobretudo, uma acepção de conhecimento que caracterize um modelo de formação amplo, composto tanto de seu espectro humanístico, quanto tecnológico.

É importante ressaltar que, no caso da Universidade Federal de Uberlândia a exigência dos conteúdos de sociologia e filosofia em seus processos de admissão fez com que as escolas públicas e particulares da cidade oferecessem em suas grandes curriculares o ensino de Filosofia e de sociologia. Desse modo:

As escolas da cidade de Uberlândia têm autonomia para adotar, ou não, a sociologia e a filosofia em sua grade curricular. Contudo, o fato de as disciplinas de estarem no elenco das matérias do vestibular e do PAIES, contribuiu de modo efetivo para que lhes houvesse sempre um espaço disponível (TOMAZINI, 2004, p. 18).

Tal acontecimento mostra a importância da cobrança dos conteúdos específicos da disciplina nos processos seletivos de admissão ao Ensino Superior. Isso é 
fundamental para que a Sociologia tenha relevância e legitimidade perante as escolas e aos alunos.

Nessa pesquisa, observou-se que, ainda que a disciplina não tenha encontrado representação e legitimidade nesses espaços, considerando a forma de apresentação de seus conteúdos nos exames de acesso ao ensino superior; um processo em curso encontra-se em franca construção. Isso nos mostra a causa do descaso da Secretaria Estadual de Educação para com a disciplina, não só pelo fato da mesma ter revogado a lei que tornava obrigatório o ensino da disciplina, mas também pelo fato de não ter havido, ou quase não haver, concursos para a contratação de professores de sociologia. Prevalecendo, dessa forma, a prática de reaproveitamento de professores de outras áreas para ministrar a disciplina.

Contudo, embora os vestibulares não tenham sido um espaço de consolidação da sociologia, a cobrança ainda tímida de seus conteúdos no Exame Nacional do Ensino Médio mostra-se como uma possibilidade no que se refere ao processo de legitimação da sociologia enquanto campo disciplinar. Todavia, para que isso de fato venha a ocorrer é preciso haver reivindicações, por parte de professores, licenciados e demais componentes da área de Ciências Sociais, pelo espaço da disciplina, que ressaltando a relevância de sua reinserção no ensino básico (CARVALHO, 2004).

Desse modo, os objetivos desta pesquisa se propuseram não apenas contribuir para o campo de estudos sobre a presença da sociologia na escola básica, mas principalmente identificar a inserção do ensino de sociologia nos processos seletivos de admissão às universidades federais mineiras durante o período de 2009 a 2013; bem como contribuir para a consolidação de grupos de pesquisa acerca destes estudos, que visem identificar a aplicação dos conteúdos do campo disciplinar. A recente projeção da sociologia clama o aprofundamento da temática, que por sua "novidade", ainda é pouco explorada no âmbito da pesquisa.

\section{Referências}

AFONSO, A. J. Avaliação educacional: regulação e emancipação: para uma sociologia das políticas avaliativas contemporâneas. $3^{\text {a }}$ ed. São Paulo: Cortez, 2005.

BARRÈRE, A; SEMBEL, N. Sociologia da Escola. $1^{\text {a }}$ ed. São Paulo: Edições Loyola, 2006. 
BRASIL. Decreto n ${ }^{\circ} 8.659$, de 5 de abril de 1911

. Decreto $\mathrm{n}^{\mathrm{o}} .11 .530$, de 18 de março de 1915

. Decreto n ${ }^{\circ} 16.782-A$ de 13 de janeiro de 1925

. Lei n. 11.684, em junho de 2008.

. Lei n. 5.540 de 28 de novembro de 1968.

. Lei n. 9.394, de 20 de dezembro de 1996

. Parâmetros Curriculares Nacionais (PCN's) - Ensino Médio/Secretaria de

Educação Média e Tecnológica.

. Orientações Curriculares para o Ensino Médio (OCEM)/Secretaria de

Educação Básica, volume 03, 2006.

CARVAlHO, L. M. G. de. A Trajetória Histórica da Luta Pela Introdução da Disciplina de Sociologia no Ensino Médio no Brasil. In: Sociologia e Ensino em Debate: Experiências e Discussão de Sociologia no Ensino Médio.

.(Org.). $1^{\text {a }}$ ed. Editora Unijuí: Ijuí, 2004.

CONCEIÇÃO, M. R; SANTOS, A. P. O Ensino de Sociologia e as Políticas Educacionais. In: GONÇALVES, D. N. (Org). Sociologia e juventude no ensino médio: formação, PIBID e outras experiências. 1ª ed. Campinas: Pontes Editores, 2013.

CUNHA, L. A. A universidade temporã: o ensino superior, da Colônia à Era Vargas. $3^{\text {a }}$ ed.São Paulo. Unesp. 2007.

FERNANDES, F. A sociologia no Brasil: contribuição para o estudo de sua formação e desenvolvimento. $2^{\text {a }}$ ed. Petrópolis: Editora Vozes, 1980.

FERREIRA, E. C. A sociologia no ensino médio: Uma experiência, in: CARVALHO, C. A. de (Org). Relação escola e universidade: a sociologia no ensino médio em perspectiva. $1^{\mathrm{a}}$ ed. Londrina: Editora EDUEL, 2010.

FOURQUIN, J. C. Introdução: Currículo e cultura. In: FOURQUIN, J- C. Escola e Cultura: As bases sociais e epistemológicas do conhecimento escolar. $1^{\mathrm{a}}$ ed. Porto Alegre: Artes Médicas, 1993.

MARTINS, R. S; SOUZA, D. T. Ensino de Sociologia e as Intermitências Curriculares: O Debate Clássico e Contemporâneo no Âmbito da Intervenção Social. In: GONÇALVES, D. N. (Org). Sociologia e juventude no ensino médio: formação, PIBID e outras experiências. $1^{\text {a }}$ ed. Campinas: Pontes Editores, 2013. 
MORAES, A. C. Licenciatura em ciências sociais e ensino de sociologia: entre o balanço e o relato. Revista Tempo Social, São Paulo, v.15, n. 01, p. 05-20, 2003.

SANTOS, J. Política pública de acesso ao ensino superior: um olhar sobre a utilização do Enem/Sisu na Universidade Federal do Recôncavo da Bahia. Disponível em:

http://www.xiconlab.eventos.dype.com.br/resources/anais/3/1308337559 ARQUIVO Artigo conlab1.pdf. > Acesso em: 01 de jul. de 2012.

SARANDY, F. M. S. O ensino de sociologia na escola média brasileira: as lutas políticas em torno de sua obrigatoriedade e as apropriações simbólicas da disciplina. In: IV Seminário de Pesquisa do Instituto de Ciência da Sociedade e Desenvolvimento Regional da Universidade Federal Fluminense. Campos, 2011.

SAVIANI, D. As teorias da educação e o problema da marginalidade. $2^{a}$ ed. São Paulo: Civilização, 1982.

SILVA, I. L. F. et al. Caderno de metodologias de ensino e de pesquisa de sociologia. $1^{a}$ ed. Paraná: Editora SETTI, 2009.

TOMAZINI, D. A; GUIMARÃES, E. da F. Sociologia no ensino médio: historicidade e perspectivas da ciência da sociedade. Relatório de pesquisa, in: CARVALHO, L. M. G. de (Org). Sociologia em debate: Experiências e discussão de sociologia no ensino médio. $1^{\text {a }}$ ed. Ijuí: Ed. Unjuí, 2004. 


\title{
A sociologia nos vestibulares: uma análise dos conteúdos da disciplina nos processos seletivos de admissão nas Universidades Federais do Estado de Minas Gerais
}

Resumo: O trabalho busca refletir sobre a consolidação da sociologia enquanto campo disciplinar, através da análise do modo como seus conteúdos foram cobrados nos processos seletivos de admissão ao Ensino Superior. Para tanto, analisaram-se as provas de admissão de onze Universidades Federais do Estado de Minas Gerais, como também as provas do Exame Nacional do Ensino Médio - ENEM, no período de 2009 a 2013. O trabalho foi realizado através de uma pesquisa qualitativa, por meio da técnica de análise dos conteúdos. Para fins de operacionalização da análise das provas utilizou-se as categorias "conteúdo disperso" e "conteúdo específico" para classificar a forma dos conteúdos de sociologia encontrados nos exames. Durante a pesquisa observou-se uma progressão lenta, mas gradativa dos conteúdos específicos de sociologia nos processos seletivos. Ainda que a maneira dispersa assumisse um caráter mais premente, nos conhecimentos acerca dos conteúdos temáticos da Sociologia, sobretudo em questões referentes a disciplinas de outras áreas das ciências humanas, não se pode negar o modesto crescimento da sociologia nesses espaços.

Palavras-chave: Ensino de Sociologia; Ensino Superior; Conteúdos curriculares

\section{Sociology in the vestibular: an analysis of the discipline contents in selective admissions processes in the Federal Universities of Minas Gerais}

\begin{abstract}
The work seeks to reflect on the consolidation of sociology as a disciplinary field, by analyzing how its contents were charged in the admission selection processes to Higher Education. Therefore, we analyzed the evidence of admission of eleven Federal University of Minas Gerais, as well as evidence from the National Survey of Secondary Education - ENEM, from 2009 to 2013. The study was conducted through a qualitative research, by means of the content analysis technique. For operational purposes the analysis of evidence used the categories "dispersed" and "specific" to classify the form of sociology of content found in surveys. During the search there was a slow progression, but gradually the specific contents of sociology in selection processes. Although dispersed manner assumed a more urgent character, knowledge about the thematic content of sociology, particularly in matters relating to disciplines from other areas of the humanities, there is no denying the modest growth of sociology in these spaces.
\end{abstract}

Keywords: Sociology of Education; Higher Education; Course content

Recebido em: 18 de abril de 2015.

Aceito para publicação em: 05 de julho de 2015 . 